\title{
OS AMBIENTES DE TRABALHO DAS EMPRESAS JUNIORES DA UNIVERSIDADE FEDERAL DE JUIZ DE FORA: ERGONOMIA E APRENDIZAGEM
}

\author{
THE JUNIOR ENTERPRISES' WORK ENVIRONMENTS OF \\ UNIVERSIDADE FEDERAL DE JUIZ DE FORA: ERGONOMICS AND \\ LEARNING
}

\author{
Joyce Falci de Aguiar, Bela. \\ Raiza Guimarães Monteiro, Bela. \\ Universidade Federal de Juiz de Fora \\ e-mail: raizamonteiro@yahoo.com.br \\ Universidade Federal de Juiz de Fora \\ e-mail: joycefalci@gmail.com
}

Empresa júnior, ergonomia, aprendizado

\begin{abstract}
Este trabalho tem como objetivo geral apresentar o projeto proposto no Trabalho de Conclusão de Curso II da Faculdade de Arquitetura e Urbanismo da Universidade Federal de Juiz de Fora, focalizado na criação de um ambiente de trabalho destinado às empresas juniores da referida instituição, aliando ergonomia e aprendizagem. Logo, foi adotada a técnica da documentação indireta, que permitiu a revisão bibliográfica sobre temas como empresa júnior, ambiente de trabalho e ergonomia. A partir de tal embasamento, foi elaborada uma proposta projetual. O projeto consiste na criação de uma nova sede para as empresas juniores, utilizando- se de aspectos da ergonomia de ambientes de trabalho compartilhados (coworking), com intuito de que com a nova configuração espacial, ocorra uma otimização dos espaços e atividades e a potencialização do aprendizado do aluno.
\end{abstract}

Junior enterprises, ergonomic, learning

The article has presented the ergonomic re-adaptation of work environments from junior enterprises in campus Universidade Federal de Juiz de Fora, which has focused on creating a work environment for the junior enterprises of this institution, combining ergonomics and learning. Therefore, the research methodology allowed the bibliographic review on the previously mentioned topics. From this foundation, a design proposal was elaborated. It consists in the adaptation of the environments of the junior enterprises to receive a new way to work, aiming a new configuration with better use of the environments and activities that enhance student learning. 
$16^{\circ}$ Ergodesign - Congresso Internacional de Ergonomia e Usabilidade de Interfaces Humano Tecnológica: Produto, Informações Ambientes Construídos e Transporte

$16^{\circ}$ USIHC - Congresso Internacional de Ergonomia e Usabilidade de Interfaces Humano Computador

CINAHPA | 2017 - Congresso Internacional de Ambientes Hipermídia para Aprendizagem.

\section{Introdução}

O ambiente de trabalho vem se modificando ao longo do tempo, e com essas transformações ocorre também a mudança nas organizações espaciais de tais ambientes. Com o crescimento do número de profissionais liberais, a escassez de espaços nos grandes centros e a especulação econômica, trabalhadores tem procurado alternativas como locações de espaços em escritórios compartilhados, os chamados coworkings. Mas para além dos motivos da escolha de tais locais de trabalho, encontram-se outros benefícios desse tipo de sistema, como o compartilhamento de ideias e tarefas.

Com este estudo, objetiva-se apresentar o projeto proposto no Trabalho de Conclusão de Curso II da Faculdade de Arquitetura e Urbanismo da Universidade Federal de Juiz de Fora, que consiste na criação de um ambiente de trabalho destinado às empresas juniores da referida instituição. Procurase aliar os aspectos ergonômicos dos ambientes compartilhados, com o objetivo da ampliação do processo de aprendizagem.

O trabalho é estruturado a partir da fundamentação teórica, que abrange os temas empresa júnior e ergonomia, na metodologia e na proposta projetual.

\section{Fundamentação teórica}

Para a elaboração do projeto, foi realizada uma fundamentação teórica a respeito das empresas juniores e sua contribuição à aprendizagem e a ergonomia dos ambientes de trabalho.

\subsection{Empresas Juniores e o aprendizado}

Considera-se Empresa Júnior, a entidade que tem funcionamento perante instituições de ensino superior e é organizada sob a forma de associação civil, gerida por estudantes matriculados em cursos de graduação de instituições de ensino superior. [BRASIL, 2016].

As empresas tem o propósito de realizar projetos e serviços que contribuam para o desenvolvimento acadêmico dos alunos, capacitando-os para o mercado de trabalho. Estão distribuídas por todo o país, sendo Minas Gerais o estado com maior número de EJs. Abrangem vários cursos, com o maior número de empresas vinculadas ao curso de engenharias e pela área das ciências sociais aplicadas [BRASIL JÚNIOR, 2014].

As empresas permitem a complementação do ensino acadêmico. $\mathrm{O}$ ambiente universitário proporciona conhecimento específico da área escolhida pelo aluno, entretanto, aliar o meio acadêmico ao trabalho pode trazer aspectos positivos. Segundo Berger, o trabalho pode possibilitar que os futuros profissionais: desenvolvam e utilizem suas habilidades e seus talentos pessoais; expressem sua energia criativa; auxiliem e orientem os companheiros de trabalho, como mentores ou como amigos; e contribuam para a comunidade oferecendo bens ou serviços [BERGER, 2003]. Portanto, explorar as potencialidades dessas empresas, pode atuar de forma a contribuir também com o processo de aprendizado do aluno.

\subsection{Aspectos ergonômicos do ambiente de trabalho}

A ergonomia é o pilar do ambiente de trabalho. Nela estão englobados os elementos capazes de interferir no indivíduo e na percepção do ambiente. Iida [2005] define ergonomia como a adaptação do trabalho ao homem, e a classifica em três categorias: a ergonomia física a cognitiva e a organizacional.

No contexto das empresas juniores, a observação organizacional dos espaços, com a união das empresas em uma mesma sede, pode permitir o contato entre as diversas áreas, em um sistema de compartilhamento, contribuindo para o aprendizado. Nesse cenário, destacam-se ambientes de trabalhos colaborativos, os chamados coworkings.

Os aspectos do coworking a serem observados com fins a aplicação deste trabalho se referem aos ideais envolvidos na construção destes ambientes: o colaborativismo, a troca de ideias entre diversas
Realização:
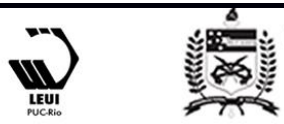


\section{$16^{\circ}$ \\ ERGODESIGN USIHC CINAHPA}

áreas, a divisão de tarefas, além da redução de custos. E para ponderações a respeito da organização espacial desses locais, deve-se considerar os diversos tipos de layouts.

Para o funcionamento de uma empresa, o papel da disposição de ambientes é importantíssimo, pois determina como as relações serão estabelecidas e qual será a hierarquia das atividades realizadas . Neste intuito surge o layout, ou planta baixa, que exerce o papel de organizar e estruturar todo o espaço de trabalho. Como definido por Couto [1996], o layout é resultado de uma composição sistemática que procura uma combinação ótima de todas as instalações, materiais e pessoas que concorrem para a fabricação de um produto ou para a execução de um serviço, dentro de um espaço disponível.

Vários autores classificam o ambiente corporativo como portador de dois tipos de layouts básicos: $\mathrm{O}$ compartimentado, composto de salas fechadas, e o em planta livre. Ambos os modelos apresentam aspectos positivos e negativos, tendo que ser consideradas às relações com o tipo de tarefa realizada. Além dos dois tipos de layouts básicos, ainda podemos destacar um terceiro, o misto, como descreve Gurgel [2008]:

-Escritório convencional ou compartimentado: Composto basicamente por salas individuais;

-Escritório em planta livre: Com surgimento nos anos 50, tem como características a utilização de divisórias baixas com móveis integrados, com a criação de estações de trabalho funcionais.

-Escritório Misto: Misto de espaços abertos e espaços privativos: e áreas sociais;

O espaço compartimentado é positivo para tarefas que despendem de maior privacidade e concentração. O escritório convencional é classificado por Iida [2005], como aquele que tem corredores definidos, proporcionam maior privacidade, sendo o preferido para algumas pessoas. Neste sentido, a noção de privacidade atua de forma positiva no ambiente, pois a falta da mesma pode resultar em fatores negativos, "a $16^{\circ}$ Ergodesign - Congresso Internacional de Ergonomia e Usabilidade de Interfaces Humano Tecnológica: Produto, Informações Ambientes Construídos e Transporte

$16^{\circ}$ USIHC - Congresso Internacional de Ergonomia e Usabilidade de Interfaces Humano Computador

CINAHPA | 2017 - Congresso Internacional de Ambientes Hipermídia para Aprendizagem.

diminuição da privacidade gera certa insatisfação" [STONE, 2001]. Contudo, a solução apresenta custo mais elevado, menos flexível e com áreas desperdiçadas, Iida [2005].

Os ambientes integrados, ou em planta livre, permitem uma maior interação entre os membros de uma empresa e a realização de trabalhos em equipe. No entanto, os estímulos devem ser medidos devido às distrações visuais, não permitindo que altos níveis tornem o trabalhador menos satisfeito e motivado, acarretando declínio na sua produtividade. Para evitar inconvenientes nos ambientes integrados, pode-se utilizar estratégias como a criação de estações de trabalho, através de divisões, estas mantêm a configuração em planta livre e diminuem as distrações visuais. Segundo Brookes e Kaplan [1972 apud Iida ], os escritórios em planta livre permitem a redução de 40 a $50 \%$ no espaço necessário. Economiza $95 \%$ nos custos e $20 \%$ no custo de manutenção.

Aumenta a produtividade em 10 a $20 \%$.

Considerando que ambos os modelos possuem aspectos positivos e negativos, pode-se considerar a utilização de um sistema misto. Visto que uma mesma empresa necessita de ambientes privativos para atividades mais exigentes de trabalho mental, bem como ambientes em planta livres para atividades que exigem menor concentração, favorecidas pela coletividade.

A figura 1 a seguir é um resumo dos tipos de layouts, considerando pontos positivos e negativos.

\begin{tabular}{|c|c|c|}
\hline \multicolumn{3}{|c|}{ TIPOS DE LAYOUT } \\
\hline $\begin{array}{c}\text { LAYOUT } \\
\text { CONVENCIONAL }\end{array}$ & $\begin{array}{c}\text { LAYOUT } \\
\text { EM PLANTA LIVRE }\end{array}$ & $\begin{array}{c}\text { LAYOUT } \\
\text { MISTO }\end{array}$ \\
\hline MAIOR PRIVACIDADE & MENOR CUSTO & \\
MISTURA DOS \\
MODELOS DE \\
LAYOUT \\
PONDERANDO \\
ASPECTOS \\
POSITIVOS E \\
NEGATIVOS \\
\hline MAIOR CUSTO & MENOR PRIVACIDADE & \\
MENOES & MAIOR FLEXIBILIDADE & \\
FLEXIBILIDADE & MAIS DISTRAÇÕES & \\
\hline
\end{tabular}

Figura 1-Quadro comparativo entre os tipos de layout Fonte: Compilação de autores: Gurgel [2008], Couto [2006] e Iida [2005]. 


\section{$16^{\circ}$ \\ ERGODESIGN USIHC CINAHPA}

Assim, no projeto do layout, vários fatores têm que ser considerados, como a natureza e o objetivos das tarefas realizadas. Deve-se também analisar a capacidade de mutação dos ambientes, a adequação espontânea ao ambiente de trabalho.

\section{Metodologia}

A metodologia utilizada foi à revisão bibliográfica e a aplicação de questionários. A revisão bibliográfica foi baseada em documentação indireta, levantamentos de material através de fontes primárias a respeito da ergonomia dos ambientes de trabalho e das empresas juniores e o processo de aprendizagem. Outra técnica utilizada foi a aplicação de questionários. O questionário é um instrumento de coleta de dados, constituído por uma série ordenada de perguntas, que devem ser respondidas por escrito e sem a presença do entrevistador [LAKATOS, 2003].

Foram aplicados 21 questionários, em membros das empresas juniores da Universidade Federal de Juiz de Fora, através dos quais foram verificadas algumas questões. A primeira refere-se a união das empresas em uma única sede. O questionamento era se os membros das empresas consideravam positiva a convivência de empresas em um mesmo espaço. A maioria dos integrantes respondeu ser positiva (17 pessoas). Algumas das justificativas foram: o benchmarking em áreas que as empresas não tem expertise, a troca de conhecimentos, a criação de parcerias e o intercâmbio de ideias.

A segunda diz respeito ao funcionamento interno da empresas. A indagação referia-se a convivência de todos os membros em um mesmo espaço, se a mesma é positiva. A maioria optou pelo sim, (16 pessoas). Algumas justificativas foram: a potencialização da produtividade e o fortalecimento dos ideais das EJs, que preza pela hierarquia horizontal. Entretanto, foram feitas ressalvas quanto a ser prejudicial a certas funções que demandam silêncio e concentração.

Através dessas respostas, pode-se inferir que a maioria dos integrantes defende a convivência entre as empresas e a convivência dos membros em um mesmo espaço. Com essas conclusões, foi $16^{\circ}$ Ergodesign - Congresso Internacional de Ergonomia e Usabilidade de Interfaces Humano Tecnológica: Produto, Informações Ambientes Construídos e Transporte

$16^{\circ}$ USIHC - Congresso Internacional de Ergonomia e Usabilidade de Interfaces Humano Computador

CINAHPA | 2017 - Congresso Internacional de Ambientes Hipermídia para Aprendizagem. elaborada a proposta projetual, com o objetivo de permitir o contato com as empresas de diversas áreas, ampliando as possibilidades de aprendizado.

\section{Proposta Projetual}

Com a revisão bibliográfica e a aplicação dos questionários foi elaborada a proposta projetual. Atualmente, a instituição conta com 13 EJs. Das treze, 12 localizam-se na própria universidade, e uma fora do campus, conforme demonstra a figura a seguir [Figura 2]:

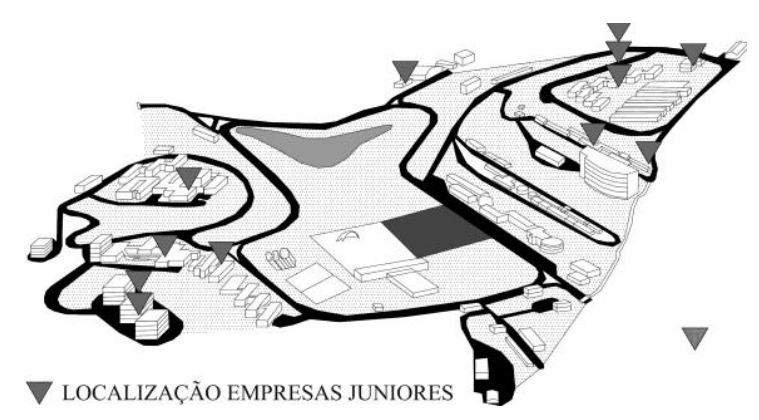

Figura 2-Localização das empresas Juniores no campus da Universidades Federal de Juiz de Fora

Fonte: Acervo próprio.

Com a revisão bibliográfica, e com os resultados averiguados em questionário, propõe-se um projeto de um novo local para as mesmas, reunido -as em uma única sede. [Figura 3].

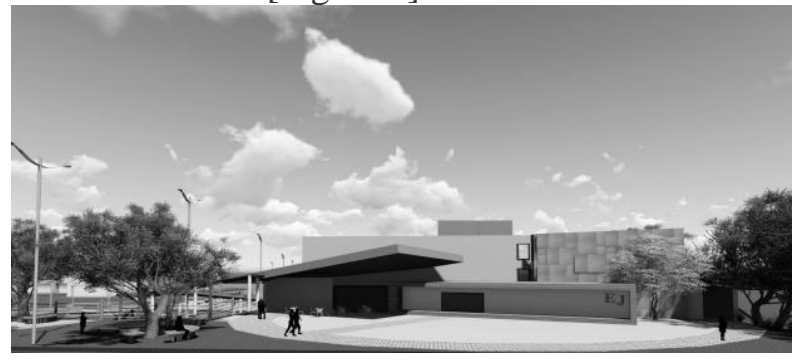

Figura 3-Proposta de nova sede para as empresas juniores da Universidade Federal de Juiz de Fora

Fonte: Acervo próprio.

O programa do projeto constitui-se de uma única edificação para todas as empresas, composta de 3 andares. A sede conta com espaços individuais para cada empresa e também áreas comuns. A figura a seguir [Figura 4] é um esquema demonstrando os fluxos principais e os ambientes propostos.
Realização:
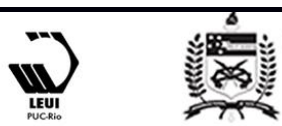

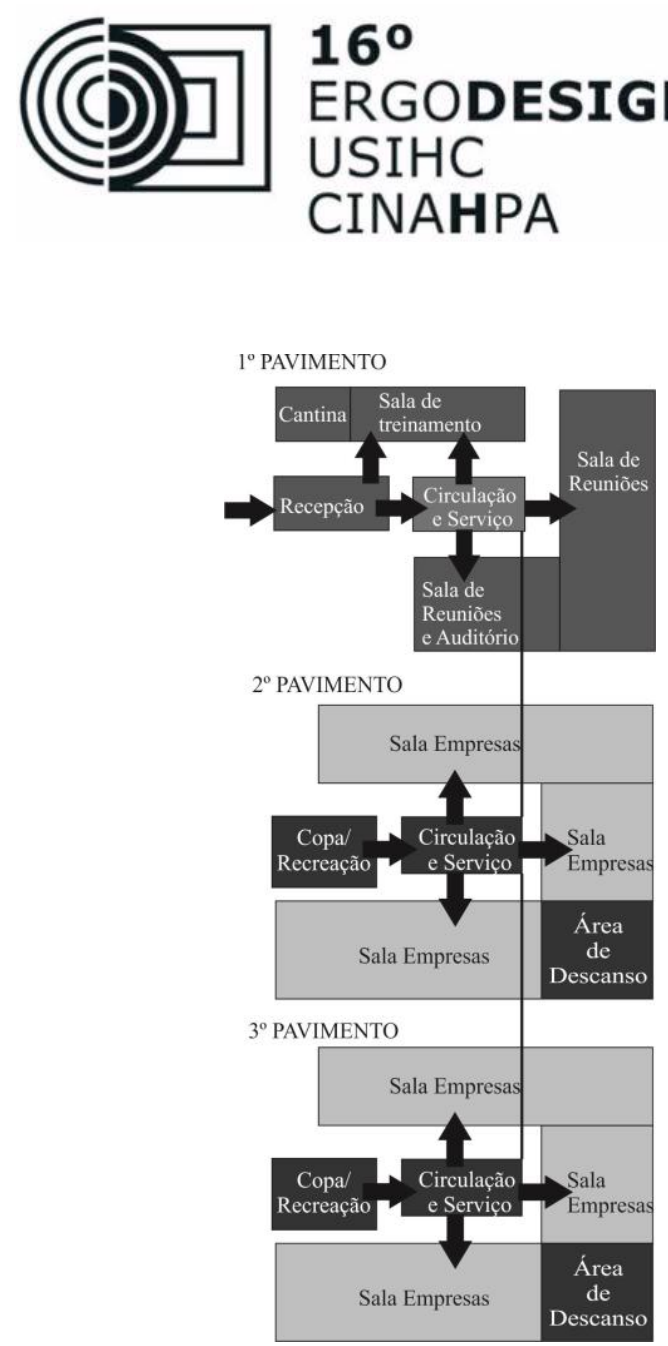

Figura 4-Esquema gráfico ambientes e fluxos

Fonte:Acervo próprio.

No primeiro pavimento, todas as áreas são comuns, o andar conta com sala de reuniões, auditório, cantina e a sala de recepção de novos membros, conforme demonstra a figura 5 :
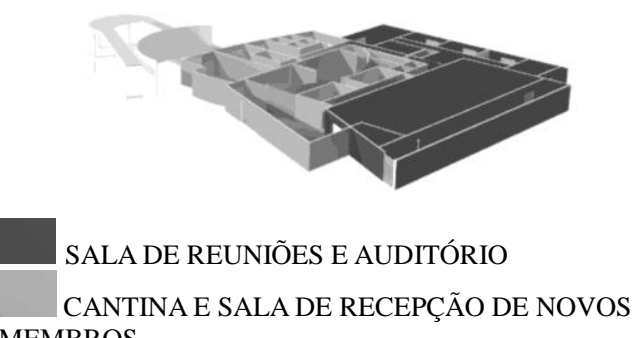
MEMBROS

Figura 5- Perspectiva isométrica $1^{\circ}$ pavimento da sede das empresas juniores

As áreas coletivas no $1^{\circ}$ pavimento permitem a convivência entre todos os membros. Sala de reuniões e auditório permitem a realização de atividades e confraternizações. A cantina atua como uma área de convivência e também é aberta ao público. A sala de recepção de novos membros $16^{\circ}$ Ergodesign - Congresso Internacional de Ergonomia e Usabilidade de Interfaces Humano Tecnológica: Produto, Informações Ambientes Construídos e Transporte

$16^{\circ}$ USIHC - Congresso Internacional de Ergonomia e Usabilidade de Interfaces Humano Computador

CINAHPA | 2017 - Congresso Internacional de Ambientes Hipermídia para Aprendizagem.

permite desde o ingresso do aluno o contato com estudantes de diferentes áreas profissionais.

A sala de recepção de novos membros possui 2 áreas, uma destinada a atividades coletivas e outras com estações de trabalho individuais [Figura 6].

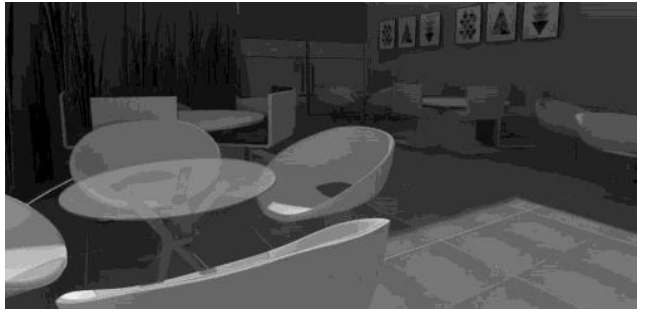

Figura 6-Imagem sala de recepção e treinamento de novos membros

Fonte: Acervo próprio

No segundo e terceiros pavimentos, cada empresa possui um espaço delimitado, composto ambientes com estações de trabalho, divididas apenas por divisórias e organização em planta livre, com mobiliário e possibilidade de realização de atividades coletivas [figura 9]. Esse tipo de layout permite com que o usuário migre entre as distintas áreas, de acordo com a tarefa a ser realizada.

Além das áreas privativas das empresas, no mesmo pavimento, propõe-se áreas compartilhas como a copa e sala de descanso. Esses espaços tem como objetivo o convívio de membros não só da própria empresa, mas também das outras empresas, promovendo o intercâmbio entre as diversas áreas.

A figura [Figura 8] a seguir demonstra como é setorizada as áreas privativas e as áreas comuns:

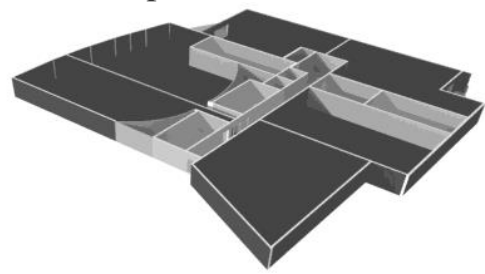

SALA DAS EMPRESAS

ÁREAS COMUNS: COPA, ÁREA DE DESCANSO

Figura 7- Perspectiva isométrica $2^{\circ}$ e $3^{\circ}$ pavimentos Fonte: Acervo próprio. 


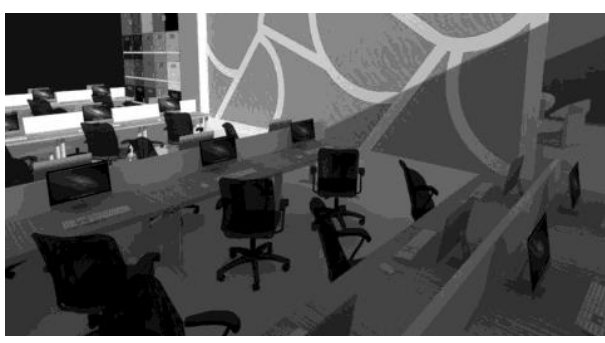

Figura 8-Imagem sala das empresas

Fonte: Acervo próprio.

Toda a divisão interna dos espaços sugerida é proposta em drywall e divisórias móveis que permitem a flexibilização futura do espaço, prevendo possíveis modificações com o decorrer do tempo.

A proposta buscou contemplar os dois tipos de layout estudados: o em planta livre e o convencional, adotando um sistema misto. A diretriz proposta é de que os espaços ofereçam a estrutura necessária para a realização das atividades individuais das empresas, mas também permitam a convivência e a realização de atividades entre empresas de áreas distintas. Dessa forma, intenciona-se que o aprendizado seja potencializado, visto o vínculo das empresas juniores com o ensino superior e as experiências e intercâmbio de ideias que essa organização espacial pode permitir ao usuário.

\section{Conclusão}

Com o estudo aqui apresentado, procurou-se entender aspectos ergonômicos dos ambientes de trabalho, bem como os tipos de layouts para a aplicação aos ambientes das empresas juniores. Ao realizar a aproximação entre os assuntos, verificase a possibilidade de contribuição da ergonomia organizacional do ambiente de trabalho atuar de forma a permitir possibilidades de interação que podem estimular o aprendizado.

Com a proposta projetual, os temas tradados foram aplicados de forma a permitir espaços privativos e individuais para cada empresa, mas contemplando áreas comuns de convivência que podem promover o compartilhamento de ideias e tarefas. $16^{\circ}$ Ergodesign - Congresso Internacional de Ergonomia e Usabilidade de Interfaces Humano Tecnológica: Produto, Informações Ambientes Construídos e Transporte

$16^{\circ}$ USIHC - Congresso Internacional de Ergonomia e Usabilidade de Interfaces Humano Computador

CINAHPA | 2017 - Congresso Internacional de Ambientes Hipermídia para Aprendizagem.

Além disso, pretende-se que mais do que suprimento de demandas inerentes ao funcionamento da empresa, a ampliação do aprendizado e a consequente melhoria da formação do aluno de instituição superior.

\section{Referências Bibliográficas}

BRASIL. lei $\mathrm{n}^{\circ}$ 13.267, de 7 de abril de 2016 . disponível em: <http://www.planalto.gov.br/ccivil_03/_ato20152018/2016/lei/113267.htm> acesso em junho de 2016.

BRASIL JÚNIOR. Censo \& Identidade Brasil Júnior. 2014. Disponível em: $<$ brasiljunior.org.br/download?file $=$ Censo $+\% 2$ 6+Identidade+2014+-+VF.pdf $>$. Acesso em junho de 2016.

BERGER, K. S. O desenvolvimento da pessoa: Do nascimento à Terceira Idade. Rio de Janeiro: LTC, 2013.

COUTO, H. A. Ergonomia aplicada ao trabalho: O manual técnico da máquina humana. Volume 2. Belo Horizonte: Ergo, 1996.

GURGEL, M. Projetando Espaços: Guia de interiores para áreas comerciais. 2ed. São Paulo: Editora Senac, 2008.

GURGEL, M. Projetando Espaços: Design de interiores. 1ed. São Paulo: Editora Senac, 2008.

IIDA, I. Ergonomia: Projeto e Produção. 2ed. São Paulo: Editora Edgard Blucher, 2005.

STONE, N. J. \& ENGLISH, A. J. Environmental view and color for a simulated telemarketing task. Journal of Environmental Psychology , v. 23, p. 63-78, 2003.Disponivel em: < http://www.sciencedirect.com/science/article/>.

\section{Agradecimentos}

Os agradecimentos são direcionados ao professor orientador do Trabalho de Conclusão de Curso II , Emmanuel Sá Resende Pedroso.
Realização:
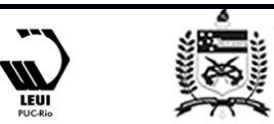